\title{
Effectiveness of In-person Tele-support Management on Perceived Burden, Health-promoting Practices, and Sense of Coherence among Caregivers of Older Adults with Parkinson's Disease
}

\author{
Marwa Ibrahim Mahfouz Khalil ${ }^{1}$, Dina Metwally Sorour ${ }^{1}$, Reem Said Shaala ${ }^{2}$, \\ Enas Fouad Sayed Mousa ${ }^{3}$
}

(1) Department of Gerontological Nursing, Faculty of Nursing, Alexandria University, Egypt.

(2) Department of Internal Medicine, Geriatric Unit, Faculty of Medicine, Alexandria University, Egypt

(3) Department of Geriatric Medicine, Faculty of Medicine, Helwan University, Egypt

Email: marwa871975@gmail.com, Tel No: 01270202044

\section{Abstract}

Introduction: The number of older adults with Parkinson's disease (PD) in need for supportive care is on the rise all over the world and the Middle East region in specific. While there are spending efforts to expand formal long-term care services to respond to this growing demand, informal care forms the backbone of this disorder. Parkinson's disease is a complex degenerative disorder that leads to cognitive decline and restricted physical abilities, which require eventually a constant care. Caregiving responsibilities are frequently bestowed upon close family members who are often thrown into caring tasks without being prepared and mostly experience the challenges of informal caregiving in association with other life demands which all require a significant amount of energy, dedication, and time-commitment. These responsibilities often become overwhelming and can lead to substantial burden with experience of mental stress and physical exhaustion related to the caring role, which may not be addressed appropriately or therapeutically. The often rapidly deteriorating condition of this disease threatens health promoting activities and sense of coherence of PD family caregivers, as the duration of care is in most cases hardly foreseeable with a challenge of lacking information about the entitlements, benefits, and support services. Related to our study, the tele-support service comprised both virtual communication, practice, and information with face-to-face or in-person meetings with peers of caregivers and the researchers (gerontological nurses and geriatricians). Setting: Conducted in El-Hadara Orthopedic and Traumatology University Hospital, specifically neuropsychiatric outpatient clinic; affiliated to Alexandria University in Alexandria, Egypt. Subjects: 39 primary and secondary PD informal caregivers recruited after fulfilling the inclusion criteria Tools: The following 4 measures were applied: (1) Demographic, caregiving experience, and support needs of caregivers of PD Older Adults Structured Interview Schedule, (2) Zarit Caregiver Burden Interview Arabic Abridged version (ZCBI-A 12 items- short version), (3) Health-promoting lifestyle Profile II - 52 items (HPLP-II scale), and (4) Antonovsky Sense of coherence scale13 items (SOC-13). Results: Family caregivers scored significantly lower on all measures of health promotion and sense of coherence, and higher on burden which were the areas of significant improvement after the application of individualized-based one-to-one interview and telephone counseling combined with group-based videoconferencing in the intervention timeframes. Age, level of education, duration and number of hours spent in caregiving, and caregivers' category are significant predictor variables. Conclusion: In-person tele-support intervention holds considerable promise in addressing efficiently and effectively caregiving challenges and stressors, resources available, and the health-promoting concerns of PD family caregivers where and when assistance is needed. It also contributes to bridging the gap between technologies, and nursing and medical care as potential conflicting dimensions 
through significant improvement in target caregiver outcomes which is the end result of enhanced acquired knowledge, caregiving experience, shared decision making, actively involved in the care process, and practiced innovative skills obtained through participation. Recommendations: Establishment of community-based and nationally funded Respite at Home care services to aid management of care recipients with PD is critically called for. Furthermore, construction of a virtual support platform dedicated to young caregivers' sector, initiation of online caregiver support web page, and accessible, affordable, tailor-made, and high-quality health-promoting and resource services for PD caregivers in the community are much needed measures.

Key words: In-person and tele support, Burden, Sense of Coherence, Health promoting practices, PD caregivers, Gerontological nurses, Geriatricians.

\begin{tabular}{|l|l|l|}
\hline Receive Date : 25/10/2020 & Accept Date: 5/11/2020 & Publish Date : 1/12/2020 \\
\hline
\end{tabular}

\section{Introduction}

While advancements in healthcare and technology allow for those with debilitating illnesses such as Parkinson's disease (PD) to promote fuller lives; a dilapidated insurance and health system in developing societies often fall short of providing long-term care within communities, leaving Parkinson's older adults faced with reduced functioning that extends to all facets of daily life, the prospect of continued decline, and the necessity of remain in palliative drug treatment until the end of their lives ${ }^{[1]}$. In addition, the rate of progression of PD varies, along with different combination, range, and severity of symptoms leading to uncertainty in the trajectory of the disease process, which is presently neither reversible nor curable. Multiple treatment options available are used to help the sufferers maintain independence and improve quality of life, not singularly treats all symptoms most come with the risk of significant motor, non-motor, and psychological side effects ${ }^{[2]}$.

Though there are options for 24-hour care in residential facilities or professional caregiving agencies, many PD older adults and their families may not rely on any of these options for caregiving needs due to expensive cost of professional health care, preference to reside in their own homes, or cultural obligation imply expectation of family-oriented caregiving ${ }^{[3]}$. Low and middle-income countries relied on informal caregivers to care for elderly family members because of the lack of financial support provided ${ }^{[4,5]}$.

Caregiving responsibilities can be stressful and daunting, and caregiver burden has both obvious and insidious effect on the informal caregivers. Caregiver perceived burden is conceptualized as a multidimensional and dynamic process in which context-specific negative affective outcome occurring because of one's perceived inability to contend with role demands ${ }^{[6]}$. This context in association with precipitating environment serve as antecedents to the stress process and lead to stressors that manifest in caregiver experiences of a lower quality of life, low level of satisfaction, excessive burden, and ultimately the decision to institutionalize the care recipient ${ }^{[7]}$. Perceived burden has both objective and subjective constituents. The objective elements are demands to which the caregiver is exposed because of caring for a dependent person. The subjective components include the way the caregiver perceives the caregiving tasks and the emotional response to caring experience ${ }^{[8]}$. Just when the emotional involvement become increasingly intense, frequent, and long-lasting; the caregiver's health and behavior may be threatened ${ }^{[9]}$. Caregivers who were providing care and experiencing caregiver burden and strain had a $63 \%$ higher risk of mortality than noncaregivers ${ }^{[10]}$. 
In PD caregiving process, burden and declined health-promoting lifestyle are greatly linked ${ }^{[11]}$. A lifestyle is the sum of all behaviors over which the individual has control, including risk behaviors and activities that belong to the regular daily pattern ${ }^{[12]}$. Health promotion behaviors (as an expression of the human tendency to update, contribute for sustaining or increasing levels of well-being, personal fulfillment, and self-actualization) should be seen by PD caregivers as a complementary component of health promotion lifestyles. The later are a multidimensional pattern of self-initialed actions and perceptions that serve to maintain or enhance the level of wellness and fulfillment of the care providers. ${ }^{[13]}$ As PD evolves into advanced stages, caregiving becomes increasingly multifaceted and time consuming and caregivers are likely to disregard their own health, as they are unlikely to pursue medical care or take steps to prevent illness ${ }^{[14]}$. Declining to take part in opportunities for self-care may put the caregiver at risk for burnout, which could unfortunately lead to maltreatment of the dependent older adults ${ }^{[15]}$.

Coming with burden is sense of coherence (SOC) which has yielded various findings as to caregivers' healthy lifestyle during the process of caregiving ${ }^{[16]}$. Antonovsky, through the salutogenesis theory, relates SOC construct to three core dimensions; comprehensibility (the way individuals make connected with their surroundings), manageability (use required resources in their reactions to certain situations), and meaningfulness (feel emotionally that these responses are adequate and meaningful). This theory focuses on resources for maintaining health and health-promoting processes. As such, SOC represents the capacity to turn available resources, flexibly and proactively, to meet the demands posed by stressors ${ }^{[17]}$. PD Caregivers SOC refers to the ability of caregivers to mobilize their adaptive coping resources during periods of caregiving to respond to stressors, avoid breakdown, alleviate mental health problems, and promote physical health ${ }^{[16]}$. Antonovsky also found that SOC, despite extremely pressing circumstances such as providing caregiving to family members, could positively help in dealing with stress or burden and protect health ${ }^{[18]}$. Within PD, SOC may promote caregiver's health through different pathways; by regulating emotional tension generated by confrontation with stressors, the selection of health-promoting behaviors, and by direct physiological consequences via the central pathways of the neuroimmune and endocrine systems ${ }^{[14]}$. SOC may influence the etiology of and recovery from any disorder by either adopting or avoiding behaviors that are directly detrimental to health. As such, SOC has been hypothesized to facilitate successful coping with caregiving stressors and the maintenance and improvement of caregivers' health ${ }^{[19]}$.

Nowadays, technology and digital health interventions is a fast-paced research field. Provision of information and practice virtually is most beneficial when tailored specifically for the individual and used as part of a multicomponent intervention ${ }^{[20]}$. Digital contact with a professional is appreciated by caregivers, who valued easy access to personalized practical advice and emotional support, leading to a reduction in burden and strain ${ }^{[21]}$. Technological delivery of health care to caregivers in their homes is increasingly feasible due to reach different geographic locations, improve the capability to monitor their conditions, coordinate care services, made it possible to transmit voices, text and pictures in real and delayed time, hence providing digital-mediated communication between persons with the expanding use of the Internet as up to $80 \%$ of caregivers of older adults are internet users ${ }^{[22]}$.

One way to practice this communication between health professionals and caregivers is by using tele-support management, which is the use of information, communication, and monitoring technologies in giving educational intervention or to deliver health and social care to caregivers in their homes" ${ }^{[23]}$. Video Conferencing (VC) and telephone contact offers potential options by incorporating audio/visual enhancements to technology-based interventions. Video conferencing allows two or more locations to connect in real-time two- 
way video and audio transmission. This type of technology enables caregivers to access healthcare services, by using the internet, without the burden of distant travel ${ }^{[24]}$.

A telephone contact, as a means of delivering support management, is an intervention that enables healthcare professionals to verbally communicate remotely with caregivers in the form of supportive advice, professional information, and psychosocial/educational support ${ }^{[25]}$. Data reports from the Egypt Ministry of Communications and Information Technology announced show a steady rise in mobile internet usage in Egypt between 2019 and 2020, increasing from 39 million in the last quarter of 2019 to 52.4 million in the same period in $2020^{[26]}$. Worldwide, over 1.3 billion are forecast to access the internet via smartphone and PC by 2025, according to a report published by the World Advertising Research Center ${ }^{[27] .}$

In tele-support groups, family caregivers meet to exchange information under the guidance of an expert discussing their stresses and strains, problems and most importantly, they experience emotional support; so, act as a form of respite for family caregivers ${ }^{[28]}$. The advantage in caregiver support group is that members are attentive and supportive to one other and share experiences and knowledge, able to help individuals relieve the pressures and burdens of caregiving, mitigate depressive symptoms, reduce angry feelings, practice coping strategies, obtain handling skills, maintain favorable health-promoting behavior and improve life quality, increase social support and satisfaction; all are expected to increase sense of coherence ${ }^{[29]}$. Professionals in health care team are the ideal choice to educate, provide informational support, and help to mobilize resources available to the informal caregivers. They have a long-term relationship that allows familiarity with the caregivers in care context and the opportunity to offer individualized intervention according to personal needs. A better understanding of the factors that influence a tele-support group's effectiveness may serve as a knowledge base for successful group design ${ }^{[30]}$.

To this date, there is little known about the caregiving situation of PD elderly patients in Egypt and the degree of challenges to which their caregivers are experienced. Additionally, application of tele-support programs for PD caregivers and investigation about their efficiency is not enough, even more lacking, or not initiated before in our sociocultural environment. In response, we initiated our research to determine the effect of in-person tele-support management on perceived burden, health-promoting practices, and sense of coherence among caregivers of older adults with Parkinson's disease.

\section{Significance of the study:}

Our community characteristics of lacking adequate referred services of PD caregivers recently considered a factor of interest to focus light on, especially with the high frequency of diagnosis with this incurable disease and the suspected elevation in abuse and institutionalization due to loaded caring process. Despite predictions that better tele-support management can positively influence the health-promoting practices and sense of coherence of Egyptian family caregivers of older adults with Parkinson's disease, there is a lack of evidence supporting this assumption. This study is the first in Egypt to help in identifying those susceptible to a higher level of caregiving burden, due to lack of ability to amalgamate health-promoting approach in the duties of those caregivers, and the unique one in integrating sense of coherence in the tele-support management protocols, not only in Egypt but also abroad. This research would enhance knowledge of services and interventions for PD caregivers who might be most vulnerable to the adverse consequences during their caregiving course.

\section{Aim of the Study:}

To determine the effect of in-person tele-support management on perceived burden, 
health-promoting practices, and sense of coherence among caregivers of older adults with Parkinson's disease.

\section{Operational definition of family care providers:}

A person who provides some type of unpaid, ongoing, and long-term assistance with activities of daily living (ADLs) or instrumental activities of daily living (IADLs) to an aging person, with a chronic illness or disability, within the home environment and who do not work in the field professionally. These caregivers have not been formally trained to provide care in the home. Caregiving includes all assistance given in the home and may range from help with fundamental activities of daily living involving dressing and mobility to transportation services, organization, and administration of medication.

\section{Operational definition of in-person tele-Support management:}

Are the internal and external resources which elucidated using combined approach of Zoom videoconferencing, tele-phone conversations, and in-person (face-to-face) interviews to provide assistance to PD caregivers in the day-to-day care of care recipients, mitigating potential caregiver burden, and improving both health-promoting activities and their sense of coherence.

\section{Research Question (s):}

- What are the domains of burden, areas of health-promoting practices, and dimensions of sense of coherence of caregivers of older adults with PD mostly affected by caring process?

- What is the effect of combined in-person tele-support management on perceived burden, health-promoting practices, and sense of coherence of caregivers of older adults with PD?

- Which significant predictor variables correlated with perceived burden, health-promoting practices, and sense of coherence of caregivers of older adults with PD?

\section{MATERIALS AND METHOD}

\section{Materials}

\section{Design:-}

Utilized a single-center Quasi-experimental research design (one group pretest posttest design).

\section{Setting and Subjects:}

Conducted in El-Hadara Orthopedic and Traumatology University Hospital, specifically neuropsychiatric outpatient clinic; affiliated to Alexandria University; and provided best services for neurological and psychiatric diseases in Alexandria, Egypt. Only Saturdays were determined for treating and following-up PD patients of all types who resides in different districts within the country zone, and mostly accompanied by their caregivers for care, support, and safety. All PD elderly patients' medical records were checked, reviewed, and verified to obtain their contact numbers for phone interviews with their caregivers, after obtaining formal approval, because unfortunately no data were available regarding caregivers to rely on. This method allowed easily and accurately reaching to the studied caregivers. Only records of elderly patients with idiopathic Parkinson's disease or degenerative parkinsonism (because other types of parkinsonism are not common in old age) were selected. Data revealed that a total of 29 PD elderly patients with their informal primary and secondary caregivers visited the clinic on specific Saturdays once per month to check status, diagnose any updates, and discuss pharmacological/therapeutic regimen or any progress. 


\section{Sample size calculation and sampling technique:}

A total of 39 care providers of elderly patients with different idiopathic Parkinson's disease stages, attending the previous clinic were eligible to participate and enrolled in the current study according to the following criteria:

1- Aged 18 years and above.

2- Only family care providers or informal caregivers (mostly adult children, siblings, and spouses) of the PD patients were included. In the case of multiple caregivers, the caregiver spending the most time with the patient and handling most of the care issues was included for the study as a primary or principal caregiver (Their number amounted to 29), secondary caregiver was the other individual who also provided assistance to the patient, but without having the principal responsibility (Their number amounted to 10). Professional paid formal caregivers were excluded from our study.

3- Only those experience negative consequences because of their caregiving as predicted on the scaling measures.

4- With no experience of previous support group attendance

5- Provided more than one year of ongoing care.

6- Spending 16-18 average caring hours as a primary caregiver, and between 6-8 hours involving in care as a secondary caregiver.

7- Without any communication problem (psychiatric disorders, etc.) that makes them difficult to interview.

8- With stable connected internet network

9- Availability of an instrument either laptop, tablet, or mobile phone with the caregiver or one of his/her nearby relative to attend the tele-videoconference.

\section{Tools: Four tools were used by the researchers for data gathering:}

Tool I: Demographic, caregiving experience, and support needs of caregivers of PD Older Adults Structured Interview Schedule (3 parts)

It was developed by the researchers based on pertinent literature to collect the following information:

Part 1): Demographic characteristics of the study subjects such as age, gender, spousal condition, level of education, occupation, and living condition (living with care recipient).

Part 2): Caregiving experience such as relationship with care recipient, duration and frequency of care, types of daily activities which needed assistance, and the possibility of changes in work, physical and psychological health, or social relationships due to care provision.

Part 3): Support needs of caregivers of PD older adults by asking caregivers to check on area(s) of caring they may need support in (multiple checks are allowed) including adequate information, dealing with symptoms, medication, assistance in the daily care from other family members, professional supervision, financial support, consultation in case of disease progression, availability of a trained and competent alternative to provide emergency care, practices to be followed to deal with behavioral and mental disorders, community resources available, dealing with negative feelings such as distress and sadness, time management, and health-related issues. 
Tool II: Zarit Caregiver Burden Interview Arabic Abridged version (ZCBI-A 12 itemsshort version):

A self-administered, standardized, and validated tool provides a comprehensive assessment of both objective and subjective distress experienced, proved to be sensitive and effective for evaluating overall burden in caregivers of older adults, and has been used to evaluate the perceived impact of providing care in different care contexts such as the caregiver's health, personal and social life, financial situation, emotional wellbeing, and interpersonal relationships. It is one of the most commonly used burden measures and has been validated in many culturally or ethnically different populations. The original format of the Zarit Caregiver Burden Interview published by Zarit et al., $1980{ }^{[31]}$ and included a 29item four-point Likert type scale. Then, an updated version was introduced by Zarit et al. $1985^{[32]}$, in which the number of items was reduced to a 22 - item five-point Likert type scale. An important advantage of the widespread use of the ZCBI allows for broader application including PD. The ZCBI was found to be a valid and reliable measure in the context of PD and confirming to be an effective tool to estimate the multidimensional burden among caregivers of community-dwelling older adults ${ }^{[33-35]}$. A short version of the ZCBI was constructed by Bedard et al., 2001 ${ }^{[36]}$, comprised of 12 items with two constructs (Similar to the original 22-item scale): (1) personal strain (consisted of nine items) and role strain (included three items). Each item on the interview is a statement which the caregiver is asked to endorse and has to indicate how often they have felt the suggested feeling or perception using a 5-point scale from 0 ('never') to 4 ('nearly always'), with a higher score representing higher sense of burden. The highest obtainable score is 48. ZCBI-12 classifies scores 0 to 10 as 'no to mild burden', 11 to 20 as 'mild to moderate burden' and scores above 20 as "moderate to high burden". This scale was translated into Arabic language by Bachner (2013) ${ }^{[37]}$ and proved to be valid and reliable in caregivers of the older adults. The Arabic version of this scale was used in the present study.

\section{Tool III: Health-promoting lifestyle Profile II - 52 items (HPLP-II scale):}

Developed by Walker \& Hill-Polerecky $(1996)^{[38]}$ aimed at measuring the likelihood of individuals engaging in health-promoting related behaviors, as a multidimensional pattern of self-initiated actions and perceptions that serve to maintain or increase the level of wellbeing, self-fulfillment, and self-satisfaction. It consists of 52 auto-responding items, with four response options varying from 1 to 4 (never, sometimes, often, routinely), within six areas. The items included on each scale are as follows: (1) Health Responsibility (nine items: 3, 9, 15, 21, 27, 33, 39, 45, 51), (2) Physical Activity (eight items: 4, 10, 16, 22, 28, 34, 40, 46), (3) Nutrition (nine items: 2, 8, 14, 20, 26, 32, 38, 44, 50), (4) Spiritual Growth (nine items: 6, 12, 18, 24, 30, 36, 42, 48, 52), (5) Interpersonal Relations (nine items: 1, 7, 13, 19, 25, 31, 37, 43, 49), (6) Stress Management (eight items: 5, 11, 17, 23, 29, 35, 41, 47). The total of the HPLP-II scale was calculated by averaging all the responses given to the 52 items (Never= 152 , Sometimes $=53-104$, Often $=105-156$, Routinely $=157-208$ ), where higher scores indicated better health-promoting practices. Six subscale scores are obtained similarly by calculating a mean of the responses to subscale items. The use of means rather than sums of scale items is recommended to retain the 1 to 4 metric of item responses and to allow meaningful comparisons of scores across subscales. The alpha coefficient of the original scale was 0.943 , and for the subscales ranging from 0.793 to 0.872 with a stability coefficient of test-retest for the whole scale of $0.892^{[38]}$.

\section{Tool IV: Antonovsky Sense of coherence scale-13 items (SOC-13)}

A shorter version of 13 reliable and valid questions (SOC-13) of the original form developed by Antonovsky (1987), who structured a questionnaire to measure the concept of 
sense of coherence. The original form, the Orientation to Life Questionnaire, consists of 29 items (SOC-29) ${ }^{[39]}$. The short form of the SOC scale consists of 13 items in which three interrelated subscales are identified: (1) Meaningfulness subscale (The motivational dimension, referred to the extent to which one feels that life has an emotional meaning, that at least some of the problems faced in life are worth commitment and dedication and are seen as challenges rather than only as burdens. Coping requires being motivated to solve the problems that causing stress, willing to invest energy to solve the problem, and finds meaning in the ability of situation management; consists of 4 items: 1, 4, 7, and 12), (2) Comprehensibility subscale (The cognitive dimension, described the extent to which one perceives internal and external stimuli as rationally understandable; consists of 5 items: 2, 6, 8, 9, and 11), (3) Manageability subscale (The instrumental or behavioral dimension, defined as the degree to which one feels that there are formal and informal resources at one's conductance that can be used to meet the requirements of the stimuli; consists of 4 items: 3, 5, 10, and 13) ${ }^{[40]}$. Participants answered indicate agreement or disagreement using 7-point semantic differential scales with two opposite anchoring phrases $(1=$ very often and $7=$ very seldom or never; where 1 and 7 indicates extreme feelings about how one's life is experienced. Score ranged from $1=$ never have this feeling to $7=$ always have this feeling.) tailored to the content of each item. Five items (1, 2, 3, 5, and 7) are reversed (Negatively worded items) before summing the total score. The total score can range from 13 to 91, and a higher score indicates higher SOC. Items were averaged to calculate the SOC score of each subject, which ranged between 1 and 7 points. When calculating the SOC score, subjects with missing values for more than 3 SOC items were treated as missing. If a subject had 3 or less SOC items with missing values, they were replaced by the mean value of the remaining SOC items for that subject. Individuals with a SOC score of 13-39 were identified as having "low SOC," those with a score of 40-65 were identified as having "moderate SOC" and those with 66-91 were identified as having "high SOC." Thus, for each participant, a total score was computed by adding up the scores for the 13 items, where higher values indicated a higher degree of SOC. The internal consistency measured by Cronbach's alpha ranges from 0.70 to 0.92 (in 127 studies) ${ }^{[41]}$.

\section{Method}

O Official letters were released from the Faculties of Nursing and Medicine, Alexandria University to the administrators of the study settings to acquire their approval to execute the study after explaining its goal. Permission was obtained from the head of the study setting who notified about the aim of the research, the period of data collection and its appointment.

○ After reviewing relevant literatures, Study tool I (Demographic, caregiving experience, and support needs of caregivers of PD Older Adults Structured Interview Schedule) was structured by the researchers in which caregivers were asked to provide general information about their background and demographics (e.g., their health history as well as the daily amount of time caregivers dedicated to giving care to the patient).

O Study tools III and IV were translated into Arabic by the researchers then, comparison between the original and translated items did not reveal any meaningful differences. Finally, an expert group of six experienced gerontological nursing and geriatric medicine professors, neurologists and PD specialists at Alexandria and Helwan Universities confirmed the validity of the translated items.

○ Tools' reliability was examined using test-retest method. This tool was applied to 10 caregivers selected from Geriatric outpatient clinic at Alexandria Main University Hospital and reapplied 2 weeks later. The reliability was assured by means of Cronbach's alpha 
(Tool II r=0.922, Tool III r=0.944, Tool IV r=0.790).

O The scales were piloted on five Parkinson's caregiver individuals (were not included in the study sample), selected from neuropsychiatric outpatient clinic in El-Hadara Orthopedic and Traumatology University Hospital before starting data collection to determine the readability, clarity, and time frame required to complete the instruments. The piloted version required approximately 40 minutes to complete which was judged to be appropriate.

\section{Preliminary state of the study:}

O The theme of our corroborative management built on using 2 combined support techniques: (1) Core virtual tele-support through video-conferencing and supplemental telephone calls and (2) In-person support through face-to-face interview. Combination of these advanced and traditional approaches is the most appropriate form/s of support for caregivers of PD older adults living at home, according to data searched. In addition, this type of different and flexible telecare service might be important in cases of internet interruption, technical errors, or inability for whatever reason to participate in video sessions a time. In-person interaction can also help respondents feel comfortable speaking about sensitive subjects of caregiving that cannot share in public ${ }^{[42]}$.

o Preparing the measurement of main outcome variables was started by selecting relevant scales and organizing the Arabic-version of the tele-support management both covered a period of approximately five months from the first of January 2019 till the middle of May 2019, after searching and reviewing up-to-dated literatures related to construction of telesupport groups and topics and contents of the sessions ${ }^{[43,44]}$.

O Meanwhile, the researchers contacted the caregivers through elementary phone call, gave hint about the aim, assessed possibility for joining, obtained verbal consent, and scheduled for the first face-to-face interview.

O According to PD patient visiting time to the clinic, each accompanied caregiver was investigated individually and selected in accordance with the inclusion criteria, then asked to rate the studied variables through signing printed paper-version of the sheet, which completed and finished within 35-40 minutes of fulfillment.

O The first evaluation of the whole members completed in nearly 6 months from the rest of May to the last of October 2019. This long period was due to limited available meeting days to only one day/ once per month for each patient and his/her associated caregiver. In addition, the secondary caregiver (if present) was also interviewed.

O Through the second in-person interview, each caregiver was given an informational sheet containing the number of sessions, methods of connecting to the tele-support group, objectives, and outlines; then asked to join telegram support group. To avoid any potential bias, the interviewers were simple blinded to the participant's group assignment.

○ Tele-videoconferencing support administration was utilized. Detailed printed-picture steps of "Zoom" download and log-in process was provided and sometimes, interviewers shared internet connection through personal hotspot helping caregiver to establish zoom cloud meetings from the play store. Then the caregivers were joined the zoom meeting through the attached links sent by researchers in telegram groups. Choosing to use Zoom videoconferencing to conduct the management was justified of its familiarity, connecting caregivers with other caregivers though group-based activities, and in providing real-time listening for immediate feedback. 


\section{Setup the environment}

O Both researchers and participants were responsible for maintaining private location that is reasonably quiet, well-lit room, avoid surrounding that might cast a shadow or create low visibility, good positioning of the camera, removing any personal items or distractions in the background, check the screen and audio quality, and maintain good eye contact and clear speak as possible. The researchers also had a back-up plan in case of technical difficulties.

\section{Conduction of the study:}

O An 18-week, open virtual support group for caregivers of PD older adults with group size of 9-10 participants each, 4 groups in total, 4 group-meeting/week, one meeting for each group weekly, 2-hour duration for each contact, with total hours of 36-hour duration of each group, 144 hours for all groups, covered a period of four months and a half, from November 2019 to mid of March 2020.

O At the beginning of virtual session, the participants' identity was verified, and they presented within view of the camera, so the researchers were aware who was participated. Moreover, the researchers confirmed that nobody recorded the sessions without permission. All participants were asked to turn off all apps and notifications on computers or smartphones. Caregivers with low educational levels were allowed to obtain help from other relatives to establish connection at the time of meeting.

O During Zoom (a video conferencing app), two of the researchers act as group facilitators in video calls. Their roles were to lead sessions, always had sound/camera on during group conduction, able, at the same time, to solve any technical challenges, and protect sessions from unauthorized access and accounts for safety.

O Within each group, the researchers presented with an overview for each session, including background information, the learning objectives, and the materials needed for the session, presentation materials for the teaching section, questions to facilitate group discussion, and Skill Building Exercises.

O Each session is structured for 120-minute each with the following five activities: Check-in (Through which, the group members shared management updates and researchers reviewed successes and barriers to previous session's goals, for 15 minutes)., Teaching (Researchers presented on the topic of the week, for 45 minutes), Skill Building (Researchers leaded group members in an exercise to practice the skills they were learnt, for 20 minutes), Discussion (Group members were asked to answer a question, described a specific experience, or discussed a topic with other group members, for 20 minutes), and Goal Setting/Wrap Up (Researchers summarized session themes. Group members planed one concrete step to take in the next week to reduce burden and improve coherence and healthpromoted activities for 20 minutes). 


\section{Description of the 18 - week in-person tele-support management:}

Session one to three components: -

Introductory session, caregivers acquiring information about disease stages and diagnosis, in addition to motor and non-motor symptoms.

○ Getting acquainted, clarify the general objectives of the sessions.

○ The importance of the tele-support program for caregivers of elderly patients with Parkinson's disease and the specific objectives to be achieved.

○ The rules that must be followed when joining a support group session.

○ Definition of the disease, causes, and leading factors.

○ Signs and symptoms that indicate Parkinson's disease, developmental stages, and diagnostic measures.

Session four to six components: -

Caregiver understanding of therapeutical guidelines and improve physical performance through executing exercise.

- Various medicines and methods for the treatment of Parkinson's disease.

○ The importance of exercise and general rules and useful tips for doing aerobic exercise and exercises to improve gait with face, neck, and chest stretches.

○ Discuss other types of stretching and flexibility exercises and how to help PD older adults to practice them.

\section{Session seven to nine components: -}

Caregiver practicing of proper body mechanics, intervening various daily activities, and using of supportive devices.

○ Correct body postures for patients and caregivers (sitting - standing - reaching for things).

○ How to avoid falls.

- Problems and challenges that change the life course in all aspects (physical, psychological, social, and recreational) and how to deal with and overcome them.

- Practical methods to increase patient's confidence in his ability to carry out the necessary daily activities which they often do as part of daily life such as bathing and using the bathtub, getting dressed, clothing and grooming, eating, sleeping, using the toilet, walking, moving, Shoes and socks (tassels), etc.

○ The auxiliary tools/ assistive devices: to maintain self-reliance for as long as possible and make daily life easier and safer such as canes, walkers, etc.

Session ten to twelve components: -

Caregiver managing of mobility, safety, and elimination.

○ Ways to improve rest and sleep, mobility and transferring, oral and dental care, writing trouble, freezing, loss of balance, reducing home hazards, resting tremors, and urination and defecation problems. 


\section{Session thirteen to fifteen components: -}

Caregiver skin care, nutrition, dealing with mental disabilities, and common emotional problems.

○ Providing skin and scalp care, dealing with sweating problems, nutritional problems, swallowing difficulties, eating accessory aids, proper nutrition, shopping and food preparation, difficulties in mental abilities, and emotional support.

Session sixteen to eighteen components: -

Mutual Social interaction, community resources available, caregiver self-care, psychological support, stress management, and health-promoting behaviors.

$\circ$ Engaging in social activities, intimacy, and family interaction, respite care planning, being oriented to community services, spiritual practices, personal health care, medical check and follow-up, recreational activities, exercising, components of well-balanced diet, overcoming communication problems, relaxation, future planning, asking for help and counseling, self-realization and achievement techniques and balancing caring requests with daily duties, needs, and responsibilities through prioritizing daily plan

- Teaching-assisted techniques used during tele-support management include active listening, problem solving, stress management, coping skills training, prioritizing needs and concerns, innovative skill building strategies, and enhanced physical activity.

- Each core tele-support session was followed by weekly follow-up brief telephone call to answer questions and provide more support. In addition, planned in-person visits at outpatient medical appointment were conducted every three weeks of tele-support (total of six times overall during management) with caregivers to receive a resource guide containing a summarized learnt materials in a brochure or pamphlet form.

- The recorded zoom videoconferencing by the facilitators was shared at the end of each meeting via Telegram (instant messaging app) which had unlimited server storage, media compression, group member number capacity, username feature, multi-plate form support, voice and videocalls, and ability of sending any kind of files.

- Following each conducted session. online resources, videos, and interactive modules were downloaded through Telegram groups for further support, description, clarification or to be a source of reference in case of offline session.

\section{Study evaluation}

O Study exposed to interruption during the constraints presented by COVID-19 era since December 2019, which affected the reassessment of study variables to compare pre and post management. To overcome this problem, phone interviews and online conversations using telegram calls groups with recording of participant's responses after obtaining consent were established.

O Some respondent engagement was difficult to maintain with administering questionnaires on the phone. To accommodate to these challenges, online data collection method through virtual google platform was used. This method promoted the safety of all shared personals within the research work and reduce time needed for completion. For respondents who were unable or unwilling to participate in online methods of data collection, in-person appointments scheduled with promotion of distance, hand washing, mask, infection control and other precautionary methods from all interested parties were followed. But even with these adjustments, the completion rate for face-to-face data collection was higher than the completion rate for virtual data collection in the dual period of secondary outcomes 
(intervention immediately effect and 6 weeks later).

O Overall period of data collection constituted around 17 months from mid of May 2019 to the last of September 2020.

Ethical aspects of the study:

An ethical approval from the Research Ethical Committee confirming the legality of the research is obtained. During the first direct contact with the caregivers, the tele-support management was presented to caregivers with a written request for voluntary participation. An information sheet is forwarded to caregivers that provided the objectives and detailed characteristics of the study. A consent form described the general and specific ethical aspects related to the right to privacy, anonymity, and confidentiality, to withdraw from the study without any penalty, and to receive study information. Participants were informed that, in order to guarantee the accuracy of study data, permission is required for researchers to gain access to the PD patients' medical records, with strict protection of the confidentiality of personal data. Only participants who provided signed informed consent were included.

Analysis strategy:

Data were fed to the computer and analyzed using IBM SPSS software package version 20.0. (Armonk, NY: IBM Corp) Qualitative data were described using number and percent. The Kolmogorov-Smirnov test was used to verify the normality of distribution Quantitative data were described using range (minimum and maximum), mean, standard deviation and median. Significance of the obtained results was judged at the $5 \%$ level.

The used tests were. 1- ANOVA with repeated measures: For normally distributed quantitative variables, to compare between more than two periods or stages, and Post Hoc test (Bonferroni adjusted) for pairwise comparisons. 2- Friedman test: For abnormally distributed quantitative variables, to compare between more than two periods or stages and Post Hoc Test (Dunn's) for pairwise comparisons. 3-Cronbach's Alpha: Reliability Statistics was assessed using Cronbach's Alpha test. 4- Spearman coefficient: To correlate between two distributed abnormally quantitative variables.

\section{Results}

Table (1) showed that recruited PD caregivers was above 40 years old (51.2\%), female (89.7\%), married (74.4\%), literate $(66.7 \%)$, and not working (56.4\%). Majority of caregivers (74.4\%) were primary caregivers, and more than half of them $(53.8 \%)$ were living with their patients. Sons or daughters constituted $38.5 \%$ of caregivers, $35.9 \%$ of them were providing care since a period ranged from 5 to less than 10 years, and $38.5 \%$ had daily care duration from 9 to 16 hours. The care provided varies according to PD older adults' needs, with care categories defined as low (mainly companionship, with some caring assistance reported by 28.2\%), medium (instrumental care such as cooking and shopping reported by $30.8 \%$ ), medium with personal assistance (such as washing and dressing reported by $35.9 \%$ ), and high (including low and medium level caring when the person receiving care cannot provide much assistance to the caregiver reported by few percent $(5.1 \%)$. Caregiving had a negative impact on their physical, psychological, and social status (66.7\%), and 53.8\% did not get any help from another one in caregiving (did not have respite care). 
Table (1): Distribution of Parkinson's caregivers according to their demographic characteristics and caregiving experience $(n=39)$.

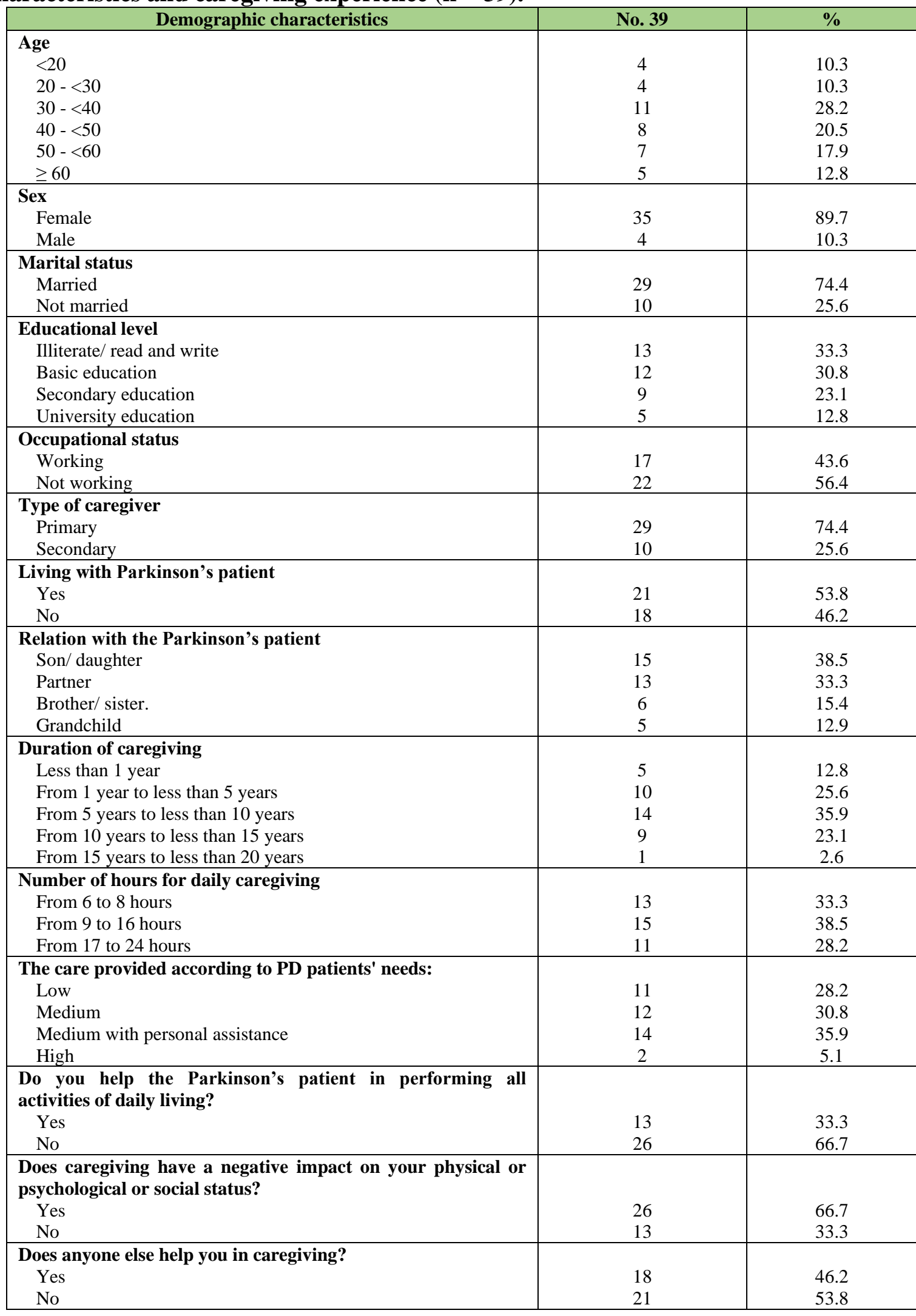

Table (2) revealed that financial support was the most common support area need (97.4\%) reported by PD caregivers, followed by information about Parkinson's disease and about the available community resources $(84.6 \%$ each), about instruments that facilitate 
caring and about proper management of disease's motor symptoms ( $76.9 \%$ each). Need to find private time for themselves, and managing negative emotions resulted from caregiving experience were reported by caregivers in significant percent $(71.8 \%, 69.2 \%$ respectively). Need to support from other family member and managing cognitive and psychological disturbance of patients were reported by $61.5 \%$ of caregivers each.

Table (2): Distribution of PD caregivers according to their support area needed $(n=39)$.

\begin{tabular}{|c|c|c|c|c|}
\hline \multirow{2}{*}{ Caregivers' support needs \# } & \multicolumn{2}{|c|}{ Yes } & \multicolumn{2}{|c|}{ No } \\
\hline & No. & $\%$ & No. & $\%$ \\
\hline Financial support to satisfy Parkinson patients' needs & 38 & 97.4 & 1 & 2.6 \\
\hline Information about Parkinson's disease and its progress & 33 & 84.6 & 6 & 15.4 \\
\hline $\begin{array}{l}\text { Knowledge about the available community resources for supporting } \\
\text { Parkinson's patients }\end{array}$ & 33 & 84.6 & 6 & 15.4 \\
\hline $\begin{array}{l}\text { Knowledge about the instruments that facilitate caring for } \\
\text { Parkinson's patient }\end{array}$ & 30 & 76.9 & 9 & 23.1 \\
\hline Managing Parkinson's motor symptoms & 30 & 76.9 & 9 & 23.1 \\
\hline Time management to find private time for themselves & 28 & 71.8 & 11 & 28.2 \\
\hline Managing negative emotions caused by caregiving such as sadness & 27 & 69.2 & 12 & 30.8 \\
\hline $\begin{array}{l}\text { Support from another family member to share in caregiving } \\
\text { responsibilities }\end{array}$ & 24 & 61.5 & 15 & 38.5 \\
\hline $\begin{array}{l}\text { Managing the cognitive and psychological disturbances among } \\
\text { Parkinson's patients }\end{array}$ & 24 & 61.5 & 15 & 38.5 \\
\hline Health promoting practices to maintain health of caregivers & 23 & 59.0 & 16 & 41.0 \\
\hline Support from formal caregiver to help in case of emergency & 16 & 41.0 & 23 & 59.0 \\
\hline
\end{tabular}

\# More than one response

Table (3) showed that the majority of PD caregivers $(79.5 \%)$ had moderate to high burden on prime pretest (before conduction), in contrast with $82.1 \%$, and $66.7 \%$ who had mild to moderate burden on the second and third posttest (following tele-support program) respectively with statistically significant determined differences $(p<0.001)$ between intervention phases.

Table (3): Comparison between the first, second, and third evaluation of Parkinson caregivers' overall score of perceived burden $(n=39)$.

Levels of burden based on Zarit Caregiver Burden Interview-12 score

No to mild burden (scores 0 to 10 )

Mild to moderate burden (scores 11 to 20)

Moderate to high burden (scores above 20)

\begin{tabular}{|c|c|c|c|c|c|c|c|}
\hline \multicolumn{2}{|c|}{$\begin{array}{c}\text { First } \\
\text { evaluation }\end{array}$} & \multicolumn{2}{c|}{$\begin{array}{c}\text { Second } \\
\text { evaluation }\end{array}$} & \multicolumn{2}{c|}{$\begin{array}{c}\text { Third } \\
\text { evaluation }\end{array}$} & \multirow{2}{*}{ Fr } & \multirow{2}{*}{ p } \\
\cline { 1 - 5 } No. & $\%$ & No. & $\%$ & No. & $\%$ & & \\
\hline 0 & 0.0 & 3 & 7.7 & 1 & 2.6 & & \\
8 & 20.5 & 32 & 82.1 & 26 & 66.7 & $38.889^{*}$ & $<0.001^{*}$ \\
31 & 79.5 & 4 & 10.3 & 12 & 30.8 & & \\
\hline
\end{tabular}

Fr: Friedman test, Sig. bet. periods was done using Post Hoc Test (Dunn's)

$\mathrm{p}$ : $\mathrm{p}$ value for comparing between the studied periods

*: Statistically significant at $\mathrm{p} \leq 0.05$

Table (4) declared that there was a statistically significant improvement $(\mathrm{p}<0.001)$ in the overall mean score of Zarit Caregiver burden Interview and its subscales after applying inperson tele-support program than before it, which totally decreased by $31.44 \%$ and $28.62 \%$ within the intervention timeframes. Personal strain was decreased by $29.5 \%$, and $28.1 \%$ on the second and third evaluation post-program, whereas role strain reduced by $34.1 \%$, and $25.2 \%$ on the previous pre-determined periods. 
Table (4): Effect of applying in-person tele-support program on the mean and standard deviation of perceived burden's subscales among PD caregivers pre-and postprogram $(\mathbf{n}=39)$.

\begin{tabular}{|c|c|c|c|c|c|}
\hline \multirow{2}{*}{$\begin{array}{c}\text { Subscales of Zarit } \\
\text { Caregiver Burden } \\
\text { Interview } \\
\end{array}$} & First evaluation & Second evaluation & Third evaluation & \multirow{2}{*}{$\mathbf{F r}$} & \multirow{2}{*}{$\mathbf{p}$} \\
\hline & Mean \pm SD. & Mean \pm SD. & Mean \pm SD. & & \\
\hline Personal Strain (0-36) & $20.10 \pm 5.43$ & $13.49 \pm 2.22$ & $13.49 \pm 5.91$ & \multirow{2}{*}{$32.686^{*}$} & \multirow{2}{*}{$<0.001$} \\
\hline$\%$ Improvement & & $-29.5 \pm 16.27$ & $-28.1 \pm 45.27$ & & \\
\hline Role Strain (0-12) & $7.41 \pm 2.28$ & $4.46 \pm 1.10$ & $4.62 \pm 2.21$ & \multirow{2}{*}{$32.956^{*}$} & \multirow{2}{*}{$<0.001$} \\
\hline$\%$ Improvement & & $-34.08 \pm 26.1$ & $-25.23 \pm 74.3$ & & \\
\hline $\begin{array}{l}\text { Total ZCBI-12 score } \\
(0-48)\end{array}$ & $27.51 \pm 7.37$ & $17.95 \pm 2.79$ & $18.10 \pm 8.0$ & \multirow[t]{2}{*}{$34.870^{*}$} & \multirow[t]{2}{*}{$<0.001^{*}$} \\
\hline$\%$ Improvement & & $-31.44 \pm 15.7$ & $-28.62 \pm 48.5$ & & \\
\hline
\end{tabular}

Fr: Friedman test, Sig. bet. periods was done using Post Hoc Test (Dunn's)

$\mathrm{p}$ : $\mathrm{p}$ value for comparing between the studied periods

*: Statistically significant at $\mathrm{p} \leq 0.05$

Table (5) illustrated that more than two thirds of caregivers $(71.8 \%)$ were sometimes practicing health promoting behaviors (scores $53-104$ ) on the first evaluation (pre-program), compared to all of them routinely practicing it on the second evaluation (scores $157-208$ ) and $92.3 \%$ of them often practicing it on the third evaluation (scores $105-156)$ post-program with statistically significant determined differences $(\mathrm{p}<0.001)$ between intervention phases.

Table (5): Comparison between the first, second, and third evaluation of Parkinson caregivers' overall score of health-promoting lifestyle $(n=39)$.

\begin{tabular}{|c|c|c|c|c|c|c|c|c|}
\hline \multirow{2}{*}{$\begin{array}{l}\text { Overall score of health- } \\
\text { promoting lifestyle }\end{array}$} & \multicolumn{2}{|c|}{$\begin{array}{c}\text { First } \\
\text { evaluation }\end{array}$} & \multicolumn{2}{|c|}{$\begin{array}{c}\text { Second } \\
\text { evaluation }\end{array}$} & \multicolumn{2}{|c|}{$\begin{array}{c}\text { Third } \\
\text { evaluation }\end{array}$} & \multirow[t]{2}{*}{$\mathbf{F r}$} & \multirow{2}{*}{$\mathbf{p}$} \\
\hline & No. & $\%$ & No. & $\%$ & No. & $\%$ & & \\
\hline Sometimes (scores $53-104$ ) & 28 & 71.8 & 0 & 0.0 & 0 & 0.0 & & \\
\hline Often (scores $105-156$ ) & 11 & 28.2 & 0 & 0.0 & 36 & 92.3 & $72.014 *$ & $<0.001 *$ \\
\hline Routinely (scores 157 - 208) & 0 & 0.0 & 39 & 100.0 & 3 & 7.7 & & \\
\hline
\end{tabular}

Fr: Friedman test, Sig. bet. periods was done using Post Hoc Test (Dunn's)

$\mathrm{p}$ : $\mathrm{p}$ value for comparing between the studied periods

*: Statistically significant at $\mathrm{p} \leq 0.05$

Table (6) revealed that there was a statistically significant enhancement $((p<0.001)$ in overall mean score of health-promoting lifestyle post in-person tele-support program than preprogram. Physical activity, health responsibility, and stress management were the most improved domains on the second $(119.7 \%, 107.6 \%$, and $94.61 \%$ respectively) and third evaluation $(69.48 \%, 60.88 \%$, and $52.12 \%$ respectively). 
Table (6): Effect of applying in-person tele-support program on mean and standard deviation of health-promoting lifestyle among the Parkinson's caregivers pre-and postthe program $(n=39)$.

\begin{tabular}{|c|c|c|c|c|c|}
\hline \multirow{2}{*}{ Health-promoting lifestyle } & First evaluation & Second evaluation & Third evaluation & \multirow{2}{*}{$\mathbf{F}$} & \multirow[b]{2}{*}{$\mathbf{p}$} \\
\hline & Mean \pm SD. & Mean \pm SD. & Mean \pm SD. & & \\
\hline Physical Activity (8-32) & $12.18 \pm 2.68$ & $25.59 \pm 1.48$ & $20.03 \pm 2.06$ & \multirow{2}{*}{$965.390^{*}$} & \multirow{2}{*}{$<0.001 *$} \\
\hline$\%$ Improvement & & $119.7 \pm 46.61$ & $69.48 \pm 25.22$ & & \\
\hline Health Responsibility (9-36) & $14.59 \pm 2.82$ & $29.23 \pm 1.83$ & $22.92 \pm 2.29$ & \multirow{2}{*}{$850.364 *$} & \multirow{2}{*}{$<0.001 *$} \\
\hline$\%$ Improvement & & $107.6 \pm 40.63$ & $60.88 \pm 21.80$ & & \\
\hline Stress Management (8-32) & $14.23 \pm 2.59$ & $26.95 \pm 1.93$ & $21.18 \pm 2.26$ & \multirow{2}{*}{$559.303^{*}$} & \multirow[b]{2}{*}{$<0.001^{*}$} \\
\hline \% Improvement & & $94.61 \pm 32.07$ & $\mathbf{t 2 2 . 5 5}$ & & \\
\hline Nutrition (9-36) & $16.85 \pm 2.70$ & $31.31 \pm 2.18$ & $24.90 \pm 2.79$ & \multirow{2}{*}{$866.202 *$} & \multirow{2}{*}{$<0.001 *$} \\
\hline$\%$ Improvement & & $89.43 \pm 25.52$ & $49.86 \pm 18.33$ & & \\
\hline Spiritual Growth (9-36) & $16.97 \pm 3.25$ & $30.03 \pm 2.32$ & $24.54 \pm 2.19$ & \multirow{2}{*}{$460.491 *$} & \multirow{2}{*}{$<0.001 *$} \\
\hline$\%$ Improvement & & $83.15 \pm 36.53$ & 48.32 \pm 22.07 & & \\
\hline Interpersonal Relations (9-36) & $17.79 \pm 3.11$ & $31.31 \pm 1.70$ & $24.90 \pm 2.05$ & \multirow{2}{*}{$538.266^{*}$} & \multirow{2}{*}{$<0.001 *$} \\
\hline$\%$ Improvement & & $80.43 \pm 28.14$ & $43.04 \pm 20.27$ & & \\
\hline $\begin{array}{l}\text { Overall health-promoting lifestyle } \\
(52-208)\end{array}$ & $92.62 \pm 15.01$ & $174.41 \pm 7.80$ & $138.5 \pm 11.15$ & \multirow[t]{2}{*}{$1045.76^{*}$} & \multirow{2}{*}{$<0.001^{*}$} \\
\hline$\%$ Improvement & & $92.83 \pm 29.69$ & $52.03 \pm 17.52$ & & \\
\hline
\end{tabular}

F: F test (ANOVA) with repeated measures, Sig. bet. Periods was done using Post Hoc Test (adjusted Bonferroni)

$\mathrm{p}$ : $\mathrm{p}$ value for comparing between the studied periods

*: Statistically significant at $\mathrm{p} \leq 0.05$

Table (7) disclosed that more than half of PD caregivers (53.8\%) had low sense of coherence on the first evaluation (pre-program), compared to $71.8 \%$ had high level on the second evaluation and $56.4 \%$ had moderate level on the third evaluation post-program with statistically significant determined differences $(\mathrm{p}<0.001)$ between intervention phases.

Table (7): Comparison between the first, second, and third evaluation of Parkinson caregivers' overall score of sense of coherence.

\begin{tabular}{|l|c|c|c|c|c|c|c|c|}
\hline \multirow{2}{*}{$\begin{array}{c}\text { Total score of Sense of } \\
\text { coherence scale }\end{array}$} & \multicolumn{2}{|c|}{$\begin{array}{c}\text { First } \\
\text { evaluation }\end{array}$} & \multicolumn{2}{c|}{$\begin{array}{c}\text { Second } \\
\text { evaluation }\end{array}$} & \multicolumn{2}{c|}{$\begin{array}{c}\text { Third } \\
\text { evaluation }\end{array}$} & \multirow{2}{*}{ Fr } & \multirow{2}{*}{ P } \\
\cline { 2 - 7 } & No. & $\%$ & No. & $\%$ & No. & \% & & \\
\hline Low (score of 13-39) & 21 & 53.8 & 0 & 0.0 & 0.0 & 0.0 & & \\
Moderate (score of 40-65) & 18 & 46.2 & 11 & 28.2 & 22 & 56.4 & $67.058^{*}$ & $<0.001^{*}$ \\
High (score of 66-91) & 0 & 0.0 & 28 & 71.8 & 17 & 43.6 & & \\
\hline
\end{tabular}

Fr: Friedman test, Sig. bet. periods was done using Post Hoc Test (Dunn's)

$\mathrm{p}$ : $\mathrm{p}$ value for comparing between the studied periods

*: Statistically significant at $\mathrm{p} \leq 0.05$

Table (8) clarified that PD caregivers had higher overall score of sense of coherence after the conduction of in-person tele-support program immediately $(65.95 \pm 6.26)$, and 6 weeks post $(61.82 \pm 6.34)$ than before $(36.49 \pm 6.75)$, with a statistically significant difference $((\mathrm{P}=<0.001)$. Comprehensibility was the most upgrading dimension and had higher percent mean score both immediately $(92.61 \%)$ and 6 weeks $(79.35 \%)$ post program. 
Table (8): Effect of applying in-person tele-support program on mean and standard deviation of sense of coherence among the Parkinson's caregivers pre-and post- the program $(n=39)$.

\begin{tabular}{|c|c|c|c|c|c|}
\hline \multirow{2}{*}{ Sense of Coherence Scale } & First evaluation & Second evaluation & Third evaluation & \multirow{2}{*}{$\mathbf{F}$} & \multirow{2}{*}{$\mathbf{p}$} \\
\hline & Mean \pm SD. & Mean \pm SD. & Mean \pm SD. & & \\
\hline Comprehensibility subscale (5-35) & $13.56 \pm 3.08$ & $25.18 \pm 2.49$ & $23.38 \pm 2.18$ & \multirow{2}{*}{$1262.649 *$} & \multirow{2}{*}{$<0.001 *$} \\
\hline$\%$ Improvement & & $92.61 \pm 35.08$ & $79.35 \pm 34.67$ & & \\
\hline Meaningfulness subscale (4-28) & $11.49 \pm 2.65$ & $20.49 \pm 2.49$ & $19.31 \pm 2.49$ & \multirow{2}{*}{$1035.313 *$} & \multirow{2}{*}{$<0.001 *$} \\
\hline$\%$ Improvement & & $85.51 \pm 34.79$ & $74.43 \pm 31.34$ & & \\
\hline Manageability subscale (4-28) & $11.44 \pm 2.64$ & $20.28 \pm 2.38$ & $19.13 \pm 2.47$ & \multirow{2}{*}{$1005.756^{*}$} & \multirow{2}{*}{$<0.001 *$} \\
\hline$\%$ Improvement & & $83.59 \pm 31.65$ & $72.92 \pm 29.44$ & & \\
\hline Overall Sense of coherence scale (13-91) & $36.49 \pm 6.75$ & $65.95 \pm 6.26$ & $61.82 \pm 6.34$ & \multirow{2}{*}{$2307.208 *$} & \multirow{2}{*}{$<0.001 *$} \\
\hline$\%$ Improvement & & $84.93 \pm 25.12$ & $73.08 \pm 22.18$ & & \\
\hline
\end{tabular}

F: F test (ANOVA) with repeated measures, Sig. bet. Periods was done using Post Hoc Test (adjusted Bonferroni) $\mathrm{p}$ : $\mathrm{p}$ value for comparing between the studied periods

*: Statistically significant at $\mathrm{p} \leq 0.05$

Table (9) reported that PD caregivers' burden level was positively correlated to increasing age, longer duration of caregiving, and more daily caregiving' hours $\left(\mathrm{p}<0.001^{*}\right)$ and negatively with higher education $\left(\mathrm{r}_{\mathrm{s}}=0.792^{*}, \mathrm{p}<0.001^{*}\right)$. Conversely, longer duration and daily hours of caregiving were negatively associated with health promoting lifestyle among PD caregivers $\left(\mathrm{p}<0.001^{*}\right)$. Whereas, increasing level of education was the predictive factor for better healthy life $\left(\mathrm{p}<0.001^{*}\right)$ and higher sense of coherence among those caregivers $(\mathrm{p}=$ $\left.0.046^{*}\right)$. Being secondary caregiver correlated positively with healthy lifestyle as the practices increased among those type of caregivers $\left(p=0.023^{*}\right)$. Moreover, it appears that higher sense of coherence and better lifestyle were significantly associated with younger- aged caregivers $\left(\mathrm{p}<0.001^{*}\right)$.

Table (9): Multivariate analyses of factors associated with perceived burden, healthpromoting lifestyle, and sense of coherence of PD caregivers $(n=39)$

\begin{tabular}{|l|c|c|c|c|c|c|}
\hline \multirow{2}{*}{\multicolumn{1}{c|}{ Factors }} & \multicolumn{2}{c|}{$\begin{array}{c}\text { Caregiver } \\
\text { perceived burden }\end{array}$} & \multicolumn{2}{c|}{$\begin{array}{c}\text { Health- } \\
\text { promoting } \\
\text { lifestyle }\end{array}$} & \multicolumn{2}{c|}{ Sense of Coherence } \\
\cline { 2 - 7 } & $\mathbf{r}_{\mathbf{s}}$ & $\mathbf{p}$ & $\mathbf{r}_{\mathbf{s}}$ & $\mathbf{p}$ & $\mathbf{r}_{\mathbf{s}}$ & $\mathbf{p}$ \\
\hline Age & $0.783^{*}$ & $<0.001^{*}$ & $-0.873^{*}$ & $<0.001^{*}$ & $-0.539^{*}$ & $<0.001^{*}$ \\
\hline Level of education & $-0.792^{*}$ & $<0.001^{*}$ & $0.789^{*}$ & $<0.001^{*}$ & $0.321^{*}$ & $0.046^{*}$ \\
\hline Duration of caregiving & $0.786^{*}$ & $<0.001^{*}$ & $-0.710^{*}$ & $<0.001^{*}$ & -0.305 & 0.059 \\
\hline Number of hours for daily caregiving & $0.726^{*}$ & $<0.001^{*}$ & $-0.773^{*}$ & $<0.001^{*}$ & $-0.357^{*}$ & $0.026^{*}$ \\
\hline Caregiver type (primary or secondary) & -0.312 & 0.053 & $0.364^{*}$ & $0.023^{*}$ & 0.059 & 0.723 \\
\hline
\end{tabular}

rs: Spearman coefficient

*: Statistically significant at $\mathrm{p} \leq 0.05$

\section{Discussion}

Caring for a dependent elderly relative has become a normative challenge for families in Egypt and throughout the world. As an Egyptian aging population and its associated disease are on the rise, the care of PD elderly patients has emerged as a major national problem ${ }^{[45]}$. According to the International Alliance of Carer Organizations 2016, the number of caregivers internationally varies according to overall population with figures varying from 60,000 in Finland to 43.5 million in the USA. This number is expected to grow by $2030^{[46]}$. Home health services offer an accessible and cost-effective supplement to the current insufficiencies of the nursing and medical system and is experiencing major growth within the health care delivery system in Egypt. As a result, family members or "hidden patients group" 
caring for PD elderly patients are taking responsibility for becoming more medically knowledgeable, implementing complex treatment plans and highly technical procedures traditionally done by professionals, planning daily schedules (e.g., dressing, cooking, activity, bathing, sleeping, medications, clinic visits, transportation) and making decisions regarding patient's life everyday challenges and problems ${ }^{[47]}$.

As many family carers of PD patients are entering their new role unprepared, accessible advanced training could help them deal with conflicts of informal care as needed. Although, caregivers of PD need training and support to face the challenge of making continuous modifications in their lives to be able to cope with escalating physical, psychological, social, and financial demands experienced by Parkinson's patient, it not easy for them to attend faceto-face programs [48, 49]. Therefore, an innovative and promising telehealth approach, conceptualized as using videoconferencing communication technology in health care services, to enhance access to educational and support group programs given for those target caregivers in remote areas $[49,50]$. For these reasons, it is logic to find a statistically significant improvement in the total percent score of the PD caregivers' burden post-program immediately and by 6 weeks $(31.4 \%, 28.62 \%$ respectively), which reflects the effectiveness of applying combined in-person tele-support group methodology by the researchers to reduce caregivers' burden.

Using telecommunication technology and its innovative apps as videoconferencing has several advantages, including its feasibility and accessibility to reach those in remote areas without the need to travel a distant clinic. Professionals can conduct a wide variety of health, psychosocial, and behavioral interventions that support caregivers' functioning regardless of location and proximity ${ }^{[25]}$. Virtual visits are also time and cost-efficient, and more convenient to the primary caregivers who could not leave their care recipients to access in-person programs. Tele-support groups are generally professional peer organized sessions aimed at building rapport among participants by having discussions regarding caregiving challenges, successes, and feelings. Videoconferencing is a valuable alternative to face-to-face visit as it allows the caregivers to contact with the researchers and other caregivers in real-time twoway video and audio for meaningful guidance and mutual support without the constraints of the other one. The reach of these interventions is significant and growing as delivery occurs any time of the day and from the comfort of the individual's home with advantages for caregivers of elderly with advanced PD had severe cognitive deficits and/or limited mobility, or those with poor access to specialized services. Multiple information formats can be adapted for those with low health literacy and content can also be readily updated or modified to incorporate other presented issues. For instance, information delivered can be presented in written or audio-visual formats, according to user needs and preferences ${ }^{[51,52]}$.

Through zoom videoconferencing, interactions facilitated between all parties as well as record usage and outcome data (such as number of logins, time spent, and content accessed) through the internet medium. These communication and automatic data connection and storage features can enhance engagement in an efficient manner. A lack of time and an inability to leave the person with PD alone are major barriers to caregivers participating in face-to-face interventions. Whereas caregivers can access electronic resources any time of the day, as often as they want. Furthermore, caregivers residing in Egyptian rural areas access to interventions in convenient locations and in turn reduce costs of respite care. Crowded urban residents as in Alexandria, with part or full-time employment also can receive needed services during off-hours, thus reducing work disruptions and potential loss of wages. Telephone intervention enables healthcare professionals to verbally communicate remotely with caregivers. In specific, interventions using combined in-person tele-support technology have been previously designed and successfully implemented for caregivers of chronically ill 
elderly patients including PD which judged as acceptable, easy to learn and user-friendly by caregivers ${ }^{[53,54]}$.

The researchers combined the new technology with traditional one to provide the opportunity to caregivers to discuss their sensitive issues privately as supplemented videoconferencing with face-to-face consultations and telephone counselling for better results. Caregivers have access to a wide array of online resources, videos, interactive modules, and other technologies to enhance their skills in stress management, emotional well-being, health status, and resources utilization. Although useful for all PD caregivers, tele-support modalities may be particularly beneficial in reaching caregivers, who are less likely to attend caregiving workshops due to financial issues, and which can be managed around their commitments. Sufficient information was given by the researchers during the program sessions about the Parkinson disease's causes and stages, its motor and non-motor symptoms, impact of Parkinson on everyday life, its pharmacological management, and different roles and responsibilities of caregivers. The researcher advises and counsels the caregivers to share caregiving responsibilities with other family members to decrease burden of care and to look for any source of respite service. On the same line, Oguh et al., (2013) argues that having access to care providers with the knowledge and skill to provide support may ease the burden of caring [55]. Shah et al., (2015) concluded that use of telephone- support groups for PD caregivers is a feasible and innovative resource to decrease caregiver burden ${ }^{[49]}$. Similar results were reported by a study done in Iran (2019) which confirmed the effectiveness of an instructional program to empower carers of elderly with PD with knowledge about the disease process and its management, and steps of problem solving in ameliorating the burden of care and improving quality of care for Parkinson's patients ${ }^{[56]}$. In the same line, Rodriguez (2017) highlighted the effectiveness of support groups in reducing caregiver burden as they act as a source of information about the available community resources that could help to reduce caregiver strain ${ }^{[57]}$.

This picture was different before conducting the supportive educational program as most caregivers $(79.5 \%)$ had moderate to high burden. This could be justified by the reported duties provided by most of the caregivers for a period ranging from 9 to 16 hours, which inflict burden upon them. Long period of care means more physical and emotional loads to the point that caring become the main activity in their life. Multitudinous roles and responsibilities including care for the disabled family member's physical and medical needs, coping with multiple loads, juggling familial roles and duties and the role of an employee with being a spouse or partner, resulted in significant disturbances of the caregivers' life and make it difficult to find spare time away from their caregiving obligation to relax or attend social activities and relieve themselves, reflecting in the imbalance between personal affairs and family function. Most importantly, caregivers who view the elderly illness as problematic or consider treatment to be stressful, feel more uncertain and hopeless. They are also much more likely to appraise the caring responsibilities negatively and tend to be emotionally distressed and show physical symptoms. In addition, financial support to satisfy Parkinson patients' needs was the primary supportive area needed by $97.4 \%$ which believed to be an initial cause of strain.

Most of Parkinson's caregivers in the current study were female $(89.7 \%)$ and $74.4 \%$ were the primary caregiver for Parkinson's patients. Females have multiple responsibilities rather than caring for patients, they have to fulfill homemaking tasks, may not have enough knowledge about the disease, leading to inability to understand their caring roles for which they were unprepared. According to Family Caregiver Alliance (2016), nearly three-fourths of caregivers are female, and the average age of a caregiver is 49.2 years of age. Male caregivers are less likely to provide personal care and more likely to assist with finances and medical 
needs. Caregivers are often related to the care recipient and are likely to be spouses or children, especially among older patients ${ }^{[46]}$. Being the primary caregivers reflected lack of the help and support from other family members in caring for Parkinson's patient, resulting in a very distressful situation for the main one. This in accordance with an Egyptian study done by Mohammed et al. (2020) which revealed that $60 \%$ of the caregivers to elderly patients with PD had moderate to severe level of burden ${ }^{[58]}$.

Moreover, in the present study, it was reported that level of education was factor that negatively correlated with the level of burden. Those with higher education had lower level of burden. This could be related to the fact that highly educated caregivers would possibly have enough knowledge about the disease and how to manage its symptoms effectively. Whereas age, duration of caregiving, and number of hours for daily caregiving positively related to the burden level. Caregivers who are older and has increasing duration of caregiving and longer hours of caring had higher level of burden. Older caregivers might have chronic illness themselves, as well as those with higher load of duties and tasks for PD patients that render caregiving to be a burden for them. Advanced research reflected a closely related liaison between caregiver burden and their health-promoting actions, as those who experiencing lower burden practice more health-promoting behaviors than those with higher burden ${ }^{[59]}$. Aggar et al., (2010) identified impaired health-maintenance factors like disrupted daily routine and sleep patterns, increased incidence of cardiovascular and metabolic diseases, lowered immunity, health problems, financial strain and a lack of family support as important causes of strain ${ }^{[60]}$.

Caregiving experience affects health and well-being of caregivers of patients with Parkinson's disease, they are often challenged with daily physical, emotional, and financial demands, which leading caregivers to neglect their own needs for sleep, nutrition, and health care and eventually can result in caregiver burnout. Most of caregivers are often overloaded with the given care and could not make a balance between caring for the person with PD and participating in activities to attend to their own health and well-being. Misunderstanding or lack of knowledge about the course of PD as well as beliefs about the moral duty of family members to provide care, possibly resulting in an unwillingness or inability to ask for help and withdrawal from wider society to care for a relative, can drive caregivers into a downward spiral of isolation, loneliness, and depression. Although they often verbalize the importance of health-promoting activities, many caregivers find it challenging to create time for self-care opportunities, to attend doctors' appointments, and to ask for caregiving assistance from other family members. Caregivers often report substantial declines in social activities, disrupted familial relationships, financial problems, and deterioration in physical and mental health. It is commonplace for family caregivers to prioritize the needs of their loved ones with chronic illnesses above their own personal concerns and lifestyle preferences. Therefore, it is sensible to find lower mean score on the different domains of health promoting lifestyle profile in the current study, mainly in physical activity, stress management, and health responsibility aspects $(12.18 \pm 2.68,14.23 \pm 2.59,14.59 \pm 2.82$ respectively) in the initial measurement before the application of tele-support group program. On the same line, a cross-sectional study in Spain (2008) revealed that most of Parkinson caregivers had poorer quality of life, more mood disorders, and higher rate of anxiety and depression than the general population ${ }^{[61]}$. A postal survey for caregivers of patients with PD in London (2006) added that over $40 \%$ of them reported that their health was affected negatively, and two-thirds reported negative consequences of caregiving on their social life $[62]$.

Besides, it was revealed in the current study that age, duration of caregiving, and number of daily hours was negatively related to health promoting lifestyle. Older caregivers 
with longer duration and more daily hours of caring would have less health- promoting practices. This is reasonable as those categories could not find enough time to care for themselves with the high prevalence of chronic illnesses, fatiguability, and dysfunctional status. On the other hand, level of education and caregiver type (primary or secondary) was positively related to healthy life, as those with higher education and secondary caregiver had more awareness about the healthy lifestyle and practicing more health promoting- related behaviors.

Health-promoting self-care behavior acted as a mediator to reduce the effect of caregiver stress on general well-being. Unfortunately, fewer researchers have studied caregiver health from a health-promotion paradigm. So, one of the most important finding in this study was a significant improvement in health-promoting lifestyle's total percent mean score after the program (92.83\%), and 6 weeks (52.03\%) compared with pre-program. The study intervention offers an effective method for promoting self-care in distressed caregivers as this mode of delivery can provide instructions about the importance of practicing activities to promote health including balanced diet, regular physical exercise, enough periods of rest and sleep, and regular check-up. In addition, counselling about time management and finding a special time for themselves to attend to their physical, emotional, and social needs was also stressed by the researchers in the educational sessions. Videoconferencing facilitated the provision of credible information and resources that enable exercising control over their lives and promote efficient communication with health care teams. It included a variety of interventions such as psychoeducation, coping strategies, self-management, and social support as well as remote monitoring, consultation (including decision support aid), social therapies, and clinical care. This result was supported by Habermann \& David (2005) who reported that caregiver education about self-care, and promotion of health and well-being was effective to improve their quality of life ${ }^{[63]}$. Prado (2020) emphasized that caregivers of people with PD who could manage their time effectively and reserve part of their time for themselves, will enjoy healthy lifestyle ${ }^{[64]}$.

One of the personality traits that helps caregivers to maintain their own health is the sense of coherence which expressed as the way in which people view a specific stressor and use the available resources within themselves and their environment to manage it effectively. Sense of coherence acts as buffer against caregiver burden and helps them to better cope with caring' stressors ${ }^{[65]}$. It is reasonable to find low sense of coherence among more than half of caregivers (53.8\%), with lower mean score of its all dimensions before commencing the telesupportive program. This could be explained by the fact that there is a limitation in the social, financial, and respite resource for Parkinson's patients. Currently in Egypt, there are no community or long-term care services for the PD elderly, which makes it difficult for patients and their families to afford expensive medical treatment and care tasks ${ }^{[58]}$. So, it seems reasonable to find a require of available community resources for supporting Parkinson's patients to be a second priority in care givers' supportive area needed (84.6\%). Moreover, most of the caregivers emphasized that they had different unmet physical, emotional, and social needs on the preliminary assessment of the present study (66.7\%). Caregivers suffering from chronic diseases usually encountered numerous negative repercussions on both physical and mental health. The most likely reason was that their disease put them at a higher risk to lose physical strength and vitality. Health care professionals always do not pay attention to the Parkinson caregivers' needs for support to reinforce their coping resources to respond effectively with the challenge of caregiving experience that including daily adjustments in their daily lifestyle ${ }^{[47]}$. This is in congruence with Villaseñor et al. study (2020) that examines relationship between family dynamics and sense of coherence among PD caregivers and recommended to develop interventions for PD family caregivers in order to improve family ability to use coping mechanisms effectively with difficulties of caregiving duties ${ }^{[16]}$. 
Furthermore, in the current study, sense of coherence was positively associated with level of education, as highly educated caregivers could manage and utilize their coping resources more effectively. On the contrary, age, duration of caregiving, and number of hours spent were negatively associated with sense of coherence. According to Family Caregiver Alliance (2016), on average, caregivers to family members spend 24.4 hours per week in a caregiver role, with $25 \%$ of family caregivers providing over 40 hours of care per week. Although the average duration of a caregiver's role is 4 years, nearly $15 \%$ of all caregivers were in this role for 10 years or more. Approximately 30\% of caregivers were in this role for less than one year. Older caregivers with longer duration and hours of caring have lower capability to efficiently using of available resources ${ }^{[46]}$.

Interestingly after the conduction of this supportive program, there was a statistically significant improvement in caregivers' total percent score of sense of coherence at the two predetermined periods of measurement $(84.93 \pm 25.12,73.08 \pm 22.18$ respectively). This may be related to the effect of the given educational sessions about the importance of the psychosocial adaptation and effective use of both emotion- and problem-solving coping strategies with the new demands of caregiving role. The researcher encourages PD caregivers to use both emotionfocused coping strategies such as meditation that aims to reduce negative emotions associated with stress, and problem-focused strategies such as problem solving which tackle the problem that is causing stress in practical ways. Moreover, utilizing in- person tele-group discussion methodology in conducting program sessions have multiple benefits for this target group. First of all, participating in a group with others facing the same physical and emotional difficulties of PD was precious in reassuring caregivers that they are not alone in this situation. Secondly, this methodology provides the opportunity to the caregivers to share their experiences of managing daily life and handling Parkinson's symptoms and to express their own negative emotions with others who could give them the advice about the effective coping strategies in similar circumstances. Chenoweth et al., (2008) and Marziali et al., (2005) supported this result and concluded that providing support to the Parkinson care partner associated with stronger sense of coherence among those caregivers ${ }^{[66,67]}$. Caregivers with a higher SOC, when providing care to the elderly, could choose the adaptive coping response and mobilize resources to handle the difficult caring circumstances. SOC could help the caregivers feel more confident in dealing with the care tasks and improving their abilities to confront stressors. SOC is an orientation to life that can help caregivers avert emotional discomforts in stressful situations and protect both mental and physical health. The caregivers with high SOC consider stressors to be more predictable and view the stressors as worthwhile and meaningful during the caring process. Support group provide caregivers with an opportunity to share their concerns and to learn how to adapt with challenges of caregiving. Navarta-Sanchez et al., (2020) added that multidisciplinary educational interventions for informal caregivers of patients with PD had a positive significant effect on the psychological adjustment and coping skills with the multiple confrontation of PD. Those caregivers need health, social, and home care services to meet their variable needs over the deteriorating course of disease ${ }^{[68]}$.

An aging global society necessitates a broad public understanding of caregiver support services. It is paramount that health-care professionals are instrumental in providing help for caregivers of patients with PD and should aim to provide the networked technology intervention means for caregiver education about PD, psychological aid, and assistance in mobilizing resources support networks. Increasingly, innovations in mobile and tablet technology must be used to adapt care for caregivers of PD. With a growing need for in-home care, families will continue to assume greater responsibility for the care of older adults experiencing debilitating physical and cognitive decline such as Parkinson's disease. Therefore, the well-being of caregivers will remain a social priority and caregiving requires a continual balancing of the caregiver's time, effort, finances, occupation, and social interests. 


\section{Conclusion:}

Individualized one-to-one interview and telephone counseling combined with groupbased video-conferencing modalities are effective tools in delivering a variety of PD caregiver skills training, resources utilization, and psychoeducational strategies with significant impacts on several target caregiver outcomes as it offers unique opportunities to reduce perceived burden and improve health-promoting behaviors and sense of coherence. The main supportive areas needed were financial support, followed by information about Parkinson's disease and about the available community resources. Age, educational level, care time and duration, and caregiving category were significant predictor variables.

\section{Recommendations}

- Constitution of available, accessible, well-known, and easily utilized support group system to all family caregivers of PD elderly patients, which concentrate primarily on moderated discussion of caregiving experiences and integrate psycho-educational elements particularly information about the illness and available treatments as well as tips on how to deal with PD patients.

- Establishment of community-based and nationally funded Respite at Home care services and infrastructures for family caregivers of PD elderly patients for the objective of providing support in the home for PD older persons by a qualified team, to relieve the informal carer from the burden of care, offer support with activities of daily living such as bathing and dressing, to educate them about how to access services, and train volunteer and paid care providers to increase the availability of respite services. Assessment of each PD patient by a multi-professional team is initiated to decide the frequency and delivery of care based on the needs of the family.

- The implementation of a national education program through weekly interactive training sessions; to support relatives of elderly living with Parkinson's disease share their experiences and build their skills to be able to better tackle stress, potential social isolation and prevent becoming physically or mentally ill themselves, in addition to construction of a support platform dedicated to young caregivers' sector to accommodate with caring responsibilities.

- Setting up of self- and mutual help groups project by trained volunteers and consultative professionals managing joint activities to provide informal carers with access to information on Parkinson care, take a break from care giving, communicate with their peers, ask for practical help, and share their information with others on a fortnightly basis. Raise awareness about the challenges of informal long-term care of PD, assess the needs of carers, and give families real choices between alternative care arrangements through education among the public, health, and social care professionals.

- Accessible, affordable, tailor-made, and high-quality health-promoting and other services in the community are much needed measures which include training, provide access to care leaves, flexible working arrangements, such as the possibility to reduce working hours or to work from home, minimize and simplify administrative procedures to improve access to temporary services such as flexible home care assistance and day-care or permanent formal care provision such as in-home nursing and medicine, in addition to improve access to information about available supportive health promoting services that enable informal carers to have time for personal lives. A special attention is directed toward ensuring income security, healthy diet, exercising program, follow-up services, psychological 
support, and social protection for informal carers including health care, income support, disease agencies and association care and availability, assistive devices, counselling, and insurance.

- Initiation of online caregiver support web page as accessing the internet allows caregivers the opportunity to explore and cope with caregiver roles and responsibilities. Interacting with other informal caregivers online could afford the caregiver the opportunity to be part of a new social support network. Communicating online also allows caregivers the opportunity to reveal information and caregiver experiences in a forum where the identity of the caregiver remained anonymous. These online networks could also allow caregivers to ask questions about caregiver burdens and receive possible solutions and coping strategies from other caregivers who experienced similar lived experiences.

\section{Further research:}

Previous studies focus on support groups with limited use of advanced management tool due to need for skill development with these technologies. Studies are needed on what knowledge nurses need to acquire of how this new technology such as telecare might expand their nursing practice and how a new tele-support practice influences positively on the lives of elders with PD and their families so that they can choose the best method of interaction.

\section{Acknowledgement}

The authors would like to offer whole appreciation to Alexandria University for support in this research. A special word of deepest gratitude is directed to the administrator of the study setting for the endless facilitations, support, and professional relationship provided during the completion of data collection. All our great thanks and indebtedness are extendedly directed to all nursing and medical staff working at the study setting, and to the caregivers of the PD older adults for their cooperation and commitment to fulfill this work.

\section{Conflict of Interest}

The authors have declared no conflict of interest.

\section{Funding}

This research did not receive any specific grant from funding agencies in the public, commercial, or not-for-profit sectors.

\section{References}

1. Kim SD, Allen NE, Canning CG, Fung VSC. Parkinson disease. Handb Clin Neurol. 2018;159:173-93.

2. Mouchaileh N, Hughes AJ. Pharmacological management of Parkinson's disease in older people. J Pharm Pract Res. 2020;50(5):445-54.

3. Alpert JM, Womble FE. Coping as a caregiver for an elderly family member. Health Commun. 2015;30(7):714-21.

4. Martinez-Martin P, Macaulay D, Jalundhwala YJ, Mu F, Ohashi E, Marshall T, et al. The long-term direct and indirect economic burden among Parkinson's disease caregivers in the United States. Mov Disord. 2019;34(2):236-45. 
5. Brinda EM, Rajkumar AP, Enemark U, Attermann J, Jacob KS. Cost and burden of informal caregiving of dependent older people in a rural Indian community. BMC Health Serv Res. 2014;14:207.

6. Ruisoto P, Ramírez M, Paladines Costa M, Vaca S, Clemente-Suárez V. Predicting Caregiver Burden in Informal Caregivers for the Elderly in Ecuador. Int J Env Res Pub He. 2020;17:1-10.

7. Macchi ZA, Koljack CE, Miyasaki JM, Katz M, Galifianakis N, Prizer LP, et al. Patient and caregiver characteristics associated with caregiver burden in Parkinson's disease: a palliative care approach. Ann Palliat Med. 2020;9(Suppl 1):S24-33.

8. Tan SB, Williams AF, Tan EK, Clark RB, Morris ME. Parkinson's Disease Caregiver Strain in Singapore. Front Neurol. 2020;11:455.

9. Hagell P, Alvariza A, Westergren A, Årestedt K. Assessment of Burden Among Family Caregivers of People With Parkinson's Disease Using the Zarit Burden Interview. J Pain Symptom Manage. 2017;53(2):272-8.

10. Schulz R, Beach SR. Caregiving as a risk factor for mortality: the Caregiver Health Effects Study. JAMA. 1999;282(23):2215-9.

11. Lim DY, Chang HJ. Behavioral and Psychological Symptoms of the Elderly with Mild Dementia in Local Communities and Care-giving Stress and Self-efficacy of Family Members. J Korea Contents Associat. 2019;19:651-62.

12. Kavga A, Govina O, Galanis P, Kalemikerakis I, Vlachou E, Fotos N, et al. Determinants of Health Promotion Behaviors among Family Caregivers of Stroke Survivors. Diseases. 2021;9(1):10.

13. Cho A, Cha C. Health Promotion Behavior among Older Korean Family Caregivers of People with Dementia. Int J Environ Res Public Health. 2021;18(8):4123.

14. Yang X, Hao Y, George SM, Wang L. Factors associated with health-related quality of life among Chinese caregivers of the older adults living in the community: a crosssectional study. Health Qual Life Outcomes. 2012;10:143.

15. Sabo K, Chin E. Self-care needs and practices for the older adult caregiver: An integrative review. Geriatr Nurs. 2021;42(2):570-81.

16. Villaseñor T, Perrin PB, Donovan EK, McKee GB, Henry RS, Dzierzewski JM, et al. Parkinson's family dynamics and caregiver sense of coherence: A family-systems approach to coping in Mexico and the United States. Aging Med (Milton). 2020;3(4):252-9.

17. Antonovsky A, Sourani T. Family sense of coherence and family adaptation. J Marriage Fam. 1988;50(1):79-92.

18. Antonovsky A. The structure and properties of the sense of coherence scale. Soc Sci Med. 1993;36(6):725-33.

19. Ekwall AK, Sivberg B, Hallberg IR. Older caregivers' coping strategies and sense of coherence in relation to quality of life. J Adv Nurs. 2007;57(6):584-96.

20. Shin JY, Choi SW. Online interventions geared toward increasing resilience and reducing distress in family caregivers. Curr Opin Support Palliat Care. 2020;14(1):60-6.

21. Shin JY, Chaar D, Hassett AL, Hanauer DA, Park SY, Debra B, et al. Harnessing mobile health technology to support long-term chronic illness management: exploring family caregiver support needs in the outpatient setting. JAMIA Open. 2020;3(4):593- 
601.

22. Kibuacha F. Report: Mobile Phone and App Usage in Africa and Asia. 2021. Available from: https://www.geopoll.com/blog/community-phone-app-usage-report-africa-asia/.

23. Handley L. Nearly three quarters of the world will use just their smartphones to access the internet by 2025. 2019. Available from: https://www.cnbc.com/2019/01/24/smartphones-72percent-of-people-will-use-onlymobile-for-internet-by-2025.html.

24. Toseland RW, Haigler DH, Monahan DJ. Education and Support Programs for Caregivers: Research, Practice, and Policy. New York: Springer company; 2011.

25. Chi NC, Demiris G. A systematic review of telehealth tools and interventions to support family caregivers. J Telemed Telecare. 2015;21(1):37-44.

26. Solli H, Bjørk IT, Hvalvik S, Helles $\varnothing$ R. Principle-based analysis of the concept of telecare. J Adv Nurs. 2012;68(12):2802-15.

27. Mallow JA, Petitte T, Narsavage G, Barnes E, Theeke E, Mallow BK, et al. The Use of Video Conferencing for Persons with Chronic Conditions: A Systematic Review. Ehealth Telecommun Syst Netw. 2016;5(2):39-56.

28. Orlando JF, Beard M, Kumar S. Systematic review of patient and caregivers' satisfaction with telehealth videoconferencing as a mode of service delivery in managing patients' health. PLoS One. 2019;14(8):e0221848.

29. Taylor A, Morris G, Pech J, Rechter S, Carati C, Kidd MR. Home Telehealth Video Conferencing: Perceptions and Performance. JMIR Mhealth Uhealth. 2015;3(3):e90.

30. Banbury A, Nancarrow S, Dart J, Gray L, Parkinson L. Telehealth Interventions Delivering Home-based Support Group Videoconferencing: Systematic Review. J Med Internet Res. 2018;20(2):e25.

31. Zarit SH, Reever KE, Bach-Peterson J. Relatives of the impaired elderly: correlates of feelings of burden. Gerontologist. 1980;20(6):649-55.

32. Zarit SH, Orr NK, Zarit JM. The hidden victims of Alzheimer's disease: Families under stress. New York: New York University Press; 1985.

33. Edwards NE, Scheetz PS. Predictors of burden for caregivers of patients with Parkinson's disease. J Neurosci Nurs. 2002;34(4):184-90.

34. Martinez-Martin P, Rodriguez-Blazquez C, Forjaz MJ, Frades-Payo B, Agüera-Ortiz L, Weintraub D, et al. Neuropsychiatric symptoms and caregiver's burden in Parkinson's disease. Parkinsonism Relat Disord. 2015;21(6):629-34.

35. Gratão ACM, Brigola AG, Ottaviani AC, Luchesi BM, Souza É N, Rossetti ES, et al. Brief version of Zarit Burden Interview (ZBI) for burden assessment in older caregivers. Dement Neuropsychol. 2019;13(1):122-9.

36. Bédard M, Molloy DW, Squire L, Dubois S, Lever JA, O'Donnell M. The Zarit Burden Interview: a new short version and screening version. Gerontologist. 2001;41(5):652-7.

37. Bachner YG. Preliminary assessment of the psychometric properties of the abridged Arabic version of the Zarit Burden Interview among caregivers of cancer patients. Eur $\mathbf{J}$ Oncol Nurs. 2013;17(5):657-60.

38. Walker S, Hill-Polerecky DM. Psychometric evaluation of health promoting lifestyle profile II. Unpublished manuscript, University of Nebraska Medical Center, College of 
Nursing 1997.

39. Antonovsky A. Unraveling the mystery of health: How people manage stress and stay well. San Francisco: Jossey-Bass Publishers; 1987.

40. Antonovsky A. The salutogenic approach to aging. A lecture held in Berkeley, 21 January 1993. Available from: https://www.angelfire.com/ok/soc/a-berkeley.html.

41. Eriksson M, Lindström B. Validity of Antonovsky's sense of coherence scale: a systematic review. J Epidemiol Community Health. 2005;59(6):460-6.

42. Solli H, Hvalvik S. Nurses striving to provide caregiver with excellent support and care at a distance: a qualitative study. BMC Health Serv Res. 2019;19(1):893.

43. Marziali E, Donahue P. Caring for others: Internet video-conferencing group intervention for family caregivers of older adults with neurodegenerative disease. Gerontologist. 2006;46(3):398-403.

44. Klemm PR, Hayes ER, Diefenbeck CA, Milcarek B. Online support for employed informal caregivers: psychosocial outcomes. Comput Inform Nurs. 2014;32(1):10-20.

45. Boggatz T, Dassen T. Ageing, care dependency, and care for older people in Egypt: a review of the literature. J Clin Nurs. 2005;14(8b):56-63.

46. International Alliance of Carer Organizations. Caregiving facts. 2020. Available from: www.internationalcarers.org/carer-facts/global-carer-stats/.

47. Theed R, Eccles F, Simpson J. Experiences of caring for a family member with Parkinson's disease: a meta-synthesis. Aging Ment Health. 2017;21(10):1007-16.

48. Genç F, Yuksel B, Tokuc FEU. Caregiver Burden and Quality of Life in Early and Late Stages of Idiopathic Parkinson's Disease. Psychiatry Investig. 2019;16(4):285-91.

49. Shah SP, Glenn GL, Hummel EM, Hamilton JM, Martine RR, Duda JE, et al. Caregiver tele-support group for Parkinson's disease: A pilot study. Geriatr Nurs. 2015;36(3):20711 .

50. Monaghesh E, Hajizadeh A. The role of telehealth during COVID-19 outbreak: a systematic review based on current evidence. BMC Public Health. 2020;20(1):1193.

51. Steffen AM, Gant JR. A telehealth behavioral coaching intervention for neurocognitive disorder family carers. Int J Geriatr Psychiatry. 2016;31(2):195-203.

52. Ni R, Liu XG, Zhu CX. Digital Health Management of long-term cared disabled elders in urban communities. Health Res. 2011;5:352-4.

53. Rush KL, Howlett L, Munro A, Burton L. Videoconference compared to telephone in healthcare delivery: A systematic review. Int J Med Inform. 2018;118:44-53.

54. Corry M, Neenan K, Brabyn S, Sheaf G, Smith V. Telephone interventions, delivered by healthcare professionals, for providing education and psychosocial support for informal caregivers of adults with diagnosed illnesses. Cochrane Database Syst Rev. 2019;5(5):Cd012533.

55. Oguh O, Kwasny M, Carter J, Stell B, Simuni T. Caregiver strain in Parkinson's disease: national Parkinson Foundation Quality Initiative study. Parkinsonism Relat Disord. 2013;19(11):975-9.

56. Bagheri S, Valizadeh Zare N, Mazlom SR, Mohajer S, Soltani M. Effect of Implementing Family-Centered Empowerment Model on Burden of Care in Caregivers of the Elderly with Parkinson's Disease. Evid Based Care. 2019;9(3):41-8. 
57. Rodriguez MR. Reducing Caregiver Burden: Fostering Healthy Aging and Social Support, Master thesis: College of Public Health, University of South Florida; 2017.

58. Mohammed AA, Elmawla D, Hassan S, Elhameed A. Relationship between Caregiving Burden and Health Status of Elderly Patients with Parkinson's Disease. IOSR Journal of Nursing and Health Science (IOSRJNHS). 2020;9(1):47-59.

59. Sisk RJ. Caregiver burden and health promotion. Int J Nurs Stud. 2000;37(1):37-43.

60. Aggar C, Ronaldson S, Cameron ID. Reactions to caregiving of frail, older persons predict depression. Int J Ment Health Nurs. 2010;19(6):409-15.

61. Martinez-Martin P, Arroyo S, Rojo-Abuin JM, Rodriguez-Blazquez C, Frades B, de Pedro Cuesta J. Burden, perceived health status, and mood among caregivers of Parkinson's disease patients. Mov Disord. 2008;23(12):1673-80.

62. Schrag A, Hovris A, Morley D, Quinn N, Jahanshahi M. Caregiver-burden in parkinson's disease is closely associated with psychiatric symptoms, falls, and disability. Parkinsonism Relat Disord. 2006;12(1):35-41.

63. Habermann B, Davis LL. Caring for family with Alzheimer's disease and Parkinson's disease: needs, challenges and satisfaction. J Gerontol Nurs. 2005;31(6):49-54.

64. Prado L, Hadley R, Rose D. Taking Time: A Mixed Methods Study of Parkinson's Disease Caregiver Participation in Activities in Relation to Their Wellbeing. Parkinsons Dis. 2020;2020:7370810.

65. Del-Pino-Casado R, Espinosa-Medina A, López-Martínez C, Orgeta V. Sense of coherence, burden and mental health in caregiving: A systematic review and metaanalysis. J Affect Disord. 2019;242:14-21.

66. Chenoweth L, Gallagher R, Sheriff JN, Donoghue J, Stein-Parbury J. Factors supporting self-management in Parkinson's disease: implications for nursing practice. Int J Older People Nurs. 2008;3(3):187-93.

67. Marziali E, Donahue P, Crossin G. Caring for others: Internet health care support intervention for family caregivers of persons with Alzheimer's, stroke, or Parkinson's disease. Fam Soc. 2005;86(3):375-83.

68. Navarta-Sánchez MV, Ambrosio L, Portillo MC, Ursúa ME, Senosiain JM, Riverol M. Evaluation of a psychoeducational intervention compared with education in people with Parkinson's disease and their informal caregivers: a quasi-experimental study. J Adv Nurs. 2020;76(10):2719-32. 